\title{
Preparing the Intensive Care Unit for Disaster
}

\author{
Randy S. Wax, MD, MEd, FRCPC, FCCM
}

\section{KEYWORDS}

- Disaster • Emergency preparedness - Disaster preparedness - Critical care

- Intensive care • Hazard-vulnerability analysis • Disaster exercise

- Disaster simulation

\section{KEY POINTS}

- Critical care disaster preparedness should balance all-hazards versus hazard-specific approaches. A critical care-specific hazard-vulnerability analysis can be conducted to identify priorities for hazard-specific planning.

- When a critical care team prepares for disaster, the entire interprofessional team should have an opportunity for input. Broad stakeholder input from other services within the hospital should also be sought, especially when planning for special populations, such as pediatric and obstetric critically ill patients.

- Critical care teams should regularly participate in disaster exercises to test and refine their plans based on immediate and delayed reflective feedback. Focus should include practice of unfamiliar tasks (eg, hospital incident command system, disaster triage, biohazard infection control) and use of disaster-specific equipment (eg, advanced personal protective equipment, stockpile mechanical ventilators).

There are 4 phases of disaster management: mitigation, preparedness, response, and recovery. This article focuses on critical care preparedness aspects of disaster management by discussing what disaster scenarios should be considered, who should be involved in disaster preparedness, and some recommendations for preparedness efforts. Effective preparedness will increase the effectiveness of disaster mitigation, disaster response, and disaster recovery. Unfortunately, interest in disaster preparedness waxes and wanes depending on the temporal proximity of the latest disaster threat, and often focuses efforts on the last disaster instead of the next one.

\section{FOR WHAT DISASTER SHOULD WE PREPARE?}

Disaster preparedness must strike a balance between all-hazards and hazard-specific approaches. The all-hazards approach takes into account generic threats to critical care demand and supply issues regardless of the cause of the disaster or surge event.

Disclosure: The author has no conflict of interest to disclose.

Department of Critical Care Medicine, Lakeridge Health, Lakeridge/Durham Clinical Hub, Queen's University, 1 Hospital Court, Oshawa, Ontario L1G 2B9, Canada

E-mail address: randy.wax@queensu.ca 
The hazard-specific approach creates a plan that is tailored to a specific type of event. Advantages and disadvantages of both approaches are summarized in Table 1. An all-hazards approach has the advantage of being potentially applicable to all possible events; however, it may create a less effective response due to lack of planning for specific challenges (eg, dialysis resources for crush injury-related renal failure after a major earthquake). A hazard-specific approach works well for the disaster events considered during planning; however, an unexpected type of event may result in a challenging response in the early stages of the disaster until the response can be recalibrated. ${ }^{2}$

Disaster preparedness efforts should include a hazard-vulnerability analysis (HVA), which evaluates risk by taking into account the likelihood of an event occurring, the severity of impact should such an event occur, the current state of preparedness, and internal/external capability to respond (RISK $=$ PROBABILITY $\times$ SEVERITY). For health care organizations, the Kaiser Permanente model provides an excellent example of such a framework and provides some online tools (such as their Hazard and Vulnerability Assessment Tool) to help hospitals prepare an HVA. ${ }^{3}$ Generating risk scores or rankings for different types of disaster events can help prioritize preparedness efforts by focusing on the most likely or most severe types of events, keeping in mind the need to maintain some level of all-hazards preparedness in case the HVA proves inaccurate or that a highly unlikely event occurs.

An HVA may be conducted from different perspectives, with different results. Federal, state/province, county/region, and local hospitals may note different probabilities, potential impact, and levels of preparedness creating different risk profiles. For example, a nuclear power plant disaster may be much less likely than natural disasters from a federal or state perspective; however, a hospital system located in close proximity to 2 nuclear power plants (such as the one in which this author practices) should likely take such events much more seriously in their planning efforts.

Even within a hospital, the results of an HVA may be more or less generalizable to different areas/programs within the hospital. The emergency department (ED) and operating room would typically experience a huge impact in a sudden onset trauma surge (such as a mass casualty shooting), whereas a bioterrorism or pandemic event with a prolonged incubation period may have a greater effect on the intensive care unit (ICU) because of the prolonged need for mechanical ventilation and ICU support for disaster-related patients. Hence the importance of involving critical care in

\begin{tabular}{|c|c|}
\hline All-Hazards approach & Hazard-Specific approach \\
\hline $\begin{array}{l}\text { Harder to prepare because of lack } \\
\text { of specific threat }\end{array}$ & Easier to prepare response to known threat \\
\hline $\begin{array}{l}\text { Onset, duration, and scale of } \\
\text { event unclear }\end{array}$ & $\begin{array}{l}\text { Onset, duration, and scale of event understood } \\
\text { during planning }\end{array}$ \\
\hline $\begin{array}{l}\text { Cannot address specific incident- } \\
\text { related concerns in advance }\end{array}$ & Specific incident-related concerns can be addressed \\
\hline $\begin{array}{l}\text { Requires a dynamic response with } \\
\text { recalibration to meet the needs } \\
\text { of a specific event }\end{array}$ & $\begin{array}{l}\text { Fixed response to specific event, but may require } \\
\text { ongoing recalibration of a minor nature }\end{array}$ \\
\hline $\begin{array}{l}\text { Prepared for initial response } \\
\text { regardless of type of disaster }\end{array}$ & $\begin{array}{l}\text { Specific hazard may not occur despite prioritization } \\
\text { through hazard-vulnerability analysis }\end{array}$ \\
\hline
\end{tabular}


hospital-wide disaster planning, but also ensuring that the critical care team conducts independent disaster preparedness activities to consider issues specific to the ICU.

\section{WHO SHOULD BE INVOLVED IN HOSPITAL CRITICAL CARE DISASTER PLANNING AND HOW CAN THEY CONTRIBUTE?}

Given that critical care is by nature an interprofessional health care effort, the need for interprofessional involvement in critical care disaster planning should be obvious. Understanding the potential roles for usual members of the critical care team in disaster planning should help guide expectations and accountabilities in the planning process. In addition, clarity of the nature of the ideal 2-way interaction with noncritical care stakeholders inside and outside the hospital is essential, thus encouraging the sharing of critical care expertise with others to help with their planning efforts and improving critical care planning with expert internal input. Table 2 highlights potential contributions of different stakeholders toward critical care disaster planning, with further details discussed below.

\section{Critical Care Physicians}

Critical care physicians possess key understanding of the nature of organ failure and support, and have day-to-day experience with patient prioritization and triage activities. Strong critical care physician presence and leadership in disaster planning is essential for developing an adequate and sustainable critical care physician resource plan for disaster events. ${ }^{4}$ As part of disaster planning, critical care physicians can help design an education strategy to prepare noncritical care physicians to assist in a disaster event as ICU physician extenders, often deployed using a just-in-time approach at the time of a disaster. Critical care physicians can also work with physicians in other areas of the hospital likely to provide critical care outside the ICU during a disaster, such as the ED, to ensure their planning takes into account critical care capacity.

\section{Critical Care Nursing and Other Providers}

As essential frontline care providers for any critically ill patient, critical care nursing must be involved in ICU disaster planning. ${ }^{5}$ Key factors for consideration include appropriate and sustainable nursing staffing (including potentially modified nurse:patient ratios), modifications to care standards if required, and documentation requirements. Planning for use of ICU nursing extenders with non-ICU nurses requires advance clarification of the scope of non-ICU nurses in caring for critically ill patients and creation of just-in-time education support to allow non-ICU nurses to augment their ability to contribute during a disaster. Critical care nursing leadership involvement will ensure adequate planning for the required interfaces between the ICU and other areas of the hospital from a patient safety and administrative perspective, including strategies for bed management and patient flow into and out of the ICU.

Advanced nursing providers, such as nurse practitioners and nurse anesthetists, ${ }^{6}$ and other providers, such as physician assistants and critical care paramedics, may provide helpful input during the planning process. In particular, these providers can help others understand how leveraging their enhanced scopes of practice may provide additional support during a severe critical care surge.

\section{Respiratory Therapists}

Respiratory therapist expertise is required to ensure appropriate planning for availability of medical gas (especially oxygen) in ICU and non-ICU clinical spaces, adequate 


\begin{tabular}{|c|c|}
\hline Stakeholder & $\begin{array}{l}\text { Potential Contributions to Critical Care Disaster } \\
\text { Planning }\end{array}$ \\
\hline Critical care physicians & $\begin{array}{l}\text { Develop physician resource plan, including strategies } \\
\text { to train and integrate non-ICU physicians into the } \\
\text { surged ICU patient care team } \\
\text { - Determine procedures for assisting other areas of the } \\
\text { hospital (eg, emergency department) during early } \\
\text { phases of a disaster before the wave of patients being } \\
\text { received by the ICU }\end{array}$ \\
\hline $\begin{array}{l}\text { Critical care nursing, advanced } \\
\text { practice nurses (nurse } \\
\text { practitioners, nurse anesthetists), } \\
\text { physician assistants, critical care } \\
\text { paramedics }\end{array}$ & $\begin{array}{l}\text { - Develop staffing strategies, including integration of } \\
\text { non-ICU nursing support into surged ICU patient care } \\
\text { team } \\
\text { - Identify opportunities to maximize scope of practice } \\
\text { and contribution from advanced providers }\end{array}$ \\
\hline Respiratory therapists & $\begin{array}{l}\text { - Planning for medical gas and ventilatory support } \\
\text { equipment, including in nontraditional care areas to } \\
\text { manage critically ill patients } \\
\text { - Education and practice with nonfamiliar stockpile } \\
\text { ventilators }\end{array}$ \\
\hline Pharmacists & $\begin{array}{l}\text { - Provide advice on appropriate medications to } \\
\text { stockpile for all-hazards and hazard-specific plans }\end{array}$ \\
\hline $\begin{array}{l}\text { Dieticians, physiotherapists, and } \\
\text { occupational therapists }\end{array}$ & $\begin{array}{l}\text { - Develop mitigation strategies to maintain adequate } \\
\text { nutrition and rehabilitation during surge demand for } \\
\text { services } \\
\text { - Create just-in-time educational tools to help family } \\
\text { members assist with rehabilitation activities }\end{array}$ \\
\hline $\begin{array}{l}\text { Mental health clinicians, social } \\
\text { workers, chaplaincy, and clinical } \\
\text { ethicists }\end{array}$ & $\begin{array}{l}\text { - Develop plan for advance stress inoculation for } \\
\text { hospital staff } \\
\text { - Plan for need to support patients, family members, } \\
\text { and hospital staff during and after a disaster }\end{array}$ \\
\hline $\begin{array}{l}\text { Trauma, emergency department, } \\
\text { and perioperative services }\end{array}$ & $\begin{array}{l}\text { - Develop plans for mutual assistance between } \\
\text { programs tailored to different phases of a disaster, } \\
\text { including need for suspension of elective surgical } \\
\text { activity } \\
\text { - Ensure mechanisms for transfer of accountability are } \\
\text { in place despite surge in patient mobility }\end{array}$ \\
\hline $\begin{array}{l}\text { Pediatric, neonatal, and obstetric } \\
\text { services }\end{array}$ & $\begin{array}{l}\text { - Determine specific equipment and supply needs to } \\
\text { support these special patient populations } \\
\text { - Anticipate need to support pediatric critical care in } \\
\text { nonpediatric hospitals during a disaster event }\end{array}$ \\
\hline $\begin{array}{l}\text { Laboratory and diagnostic imaging } \\
\text { services }\end{array}$ & $\begin{array}{l}\text { - Plan for enhanced point-of-care testing/studies to } \\
\text { expedite clinical decision making and reduce demand } \\
\text { on overwhelmed staff }\end{array}$ \\
\hline $\begin{array}{l}\text { Facilities and information } \\
\text { technology }\end{array}$ & $\begin{array}{l}\text { - Prepare for modifications to create more negative- } \\
\text { pressure airborne isolation space } \\
\text { - Ensure adequate and flexible network coverage to } \\
\text { allow use of mobile computers in makeshift clinical } \\
\text { areas }\end{array}$ \\
\hline Security & $\begin{array}{l}\text { - Anticipate access control needs for traditional and } \\
\text { makeshift critical care clinical areas }\end{array}$ \\
\hline
\end{tabular}




\begin{tabular}{|ll|}
\hline $\begin{array}{l}\text { Table } 2 \\
\text { (continued) }\end{array}$ & \\
Stakeholder & $\begin{array}{l}\text { Potential Contributions to Critical Care Disaster } \\
\text { Planning }\end{array}$ \\
\hline & $\begin{array}{l}\text { Provide support for staff during challenging } \\
\text { interactions with family members, particularly during } \\
\text { communication of triage decisions }\end{array}$ \\
\hline Administration and finance & $\begin{array}{l}\text { Provide support for critical care disaster preparedness } \\
\text { activities }\end{array}$ \\
& - Secure external funding when possible to offset the \\
& $\begin{array}{l}\text { costs of disaster preparedness (eg, medication and } \\
\text { equipment stockpiles, staff education) }\end{array}$ \\
\hline
\end{tabular}

access to airway equipment and mechanical ventilators, and planning for provision of respiratory support in non-ICU areas of the hospital. ${ }^{7}$ Strategies for enhancing capacity for mechanical ventilation may rely on use of unfamiliar ventilators from an external stockpile, or use of modified ventilators (such as transport ventilators or anesthesia gas machines). Respiratory therapists may also help with other aspects of hazard-specific preparedness, such as strategies for monitoring of carbon monoxide in mass casualty exposures or delivery of bronchodilators for patients exposed to pulmonary irritants. In many jurisdictions, respiratory therapists with maximized scope of practice can also provide support for nonrespiratory issues, such as intravenous insertion or medication delivery, that can be incorporated into planning for provider oversight of patients during a major surge event.

\section{Pharmacists}

Appropriate stockpiling of medications is an essential component of critical care disaster preparedness, for which pharmacist input is invaluable. ${ }^{8}$ From an all-hazards perspective, generic medication requirements for management of ICU patients can be modeled, such as need for sedation and analgesia for ventilated patients, or preventative therapy such as deep venous thrombosis prophylaxis. Hazard-specific planning can include medications specific to address the hazard, such as antidotes for organophosphate poisoning, cyanide exposure treatment, or antiviral medications for pandemic influenza. The ICU-specific HVA can help pharmacists prioritize medication planning during disaster preparedness activities. Knowledge of factors such as shelf life of medications, need for special storage such as refrigeration, and costing helps pharmacists provide essential advice for procurement. Ideally, stockpiling strategies will avoid unnecessary availability of multiple drugs that can provide the same effect, such as having morphine and fentanyl and hydromorphone available as multiple narcotics. Pharmacy input for creation of preprinted order sets to be used during a disaster can help align prescribing by providers with the available drugs stockpiled. Finally, given that funds used for disaster preparedness take away from funds required for usual hospital expenses, pharmacy input on cost:benefit ratios of different medication options can help with a fiscally responsible approach to disaster planning and logistics.

\section{Dieticians, Physiotherapists, and Occupational Therapists}

Maintaining appropriate nutrition, early mobilization, and encouraging improved recovery to baseline functional state are essential adjuncts to life-support efforts. Encouraging the involvement of relevant interprofessional team members in critical care disaster planning can help determine potential limitations in services during a 
disaster, suggest mitigation strategies to minimize the impact of a surge in demand for their expertise, and propose educational strategies to use other health care staff and even family members to assist as extenders with less frequent available input from these health care professionals.

\section{Mental Health Clinicians, Social Workers, Chaplaincy, and Clinical Ethicists}

Critical care disaster planning should take into account the tremendous stress of such events on patients, families and clinical staff. More detailed discussion of these issues can be found in other articles in this issue. Although prehospital and ED triage strategies should identify and support disaster victims with isolated psychological/mental health issues, nothing precludes the copresence of mental health injuries (novel or exacerbations of existing mental health diagnoses) with critical illness from physical causes. Planning for availability of psychiatry and other mental health consultationliaison services should be considered to support patients requiring critical care after a disaster. Similarly, family members of critically ill patients will require ongoing support throughout the hospitalization of their loved ones, which may include need for social work and chaplaincy. Strategies to ensure effective communication and support of family members when patients require transfer out of the hospital for higher level of care or capacity reasons should be considered in planning efforts. Withdrawal of active life support may be required when patients are not benefiting from critical care support and/or if triage decision making requires shifting of resources to patients more likely to benefit, and the involvement of clinical ethicists to support patients, families, and staff members can be very helpful thus requiring consideration during planning. ${ }^{9}$ An emerging concept in disaster planning incorporates the concept of mental health/stress inoculation for hospital staff, which may include advance and just-intime deployment to increase performance during the disaster and prevent long-term psychological effects. ${ }^{10,11}$

\section{Trauma, Emergency Department, and Perioperative Services}

During events that cause a sudden and rapid surge of patients to the hospital with mass casualty medical issues, trauma/burns, or other injuries requiring surgical support, impact on the ICU can be delayed but substantial as the disaster unfolds. In such circumstances, the ED is usually on the frontline as first receivers of critically ill patients. The ED and ICU teams must collaborate during disaster planning to ensure that critically ill patients receive optimal care regardless of their geographic location within the hospital. In the early stages of a disaster, ICU planning may need to include a time-limited option to have critical care clinicians support patient care and triage activities in the ED. Many patients will require resuscitation and stabilization in the ED before being safe to transport to the ICU, and may also require transfer to the operating room for damage control or definitive surgery before transfer to the ICU. Planning for the orderly and safe transfer of patients from the ED or the operating room to the ICU should include strategies for efficient transfer of clinical information and accountability of care.

In the event of a nonsurgical disaster creating severe patient surge within the ICU and hospital as a whole, disaster planning should include procedures for decision making regarding the cancellation of elective surgery to augment availability of space, staff and, supplies for disaster-related patients. ${ }^{12}$ Plans for using surgical resources to support critically ill patients in the postoperative recovery room area (as an extended ICU) or operating rooms (using anesthetic gas machine ventilators) should be discussed collaboratively. 


\section{Pediatrics, Neonatal, and Obstetric Services}

Pediatric specialty hospitals that have a distinct pediatric critical care unit often provide regional support for critically ill and injured children. In a disaster event, the dedicated pediatric critical care center may be overwhelmed with patients, or the nature of the disaster may preclude immediate transfer of pediatric patients. Therefore, nonpediatric hospitals should plan for management of pediatric patients. This would require potential stockpiling of equipment and supplies appropriate for pediatric patients. Advance or just-in-time education for nonpediatric critical care providers to manage critically ill children should be considered (1 course currently recommended for this purpose in some jurisdictions is the Pediatric Fundamental Critical Care Support Course offered by the Society of Critical Care Medicine ${ }^{13,14}$ ), as well as planned partnership with pediatricians to comanage critically ill children with adult intensivists.

A disaster may force hospitals to care for obstetric patients beyond their usual complexity case mix or with gestational age earlier than usual, resulting in neonatal patients requiring more support than usually provided at the facility. These patients may have issues related to the disaster, or may be unable to be transferred because of the overwhelming surge in the usual tertiary care facility or because of the disrupted patient transport resources. From a critical care perspective, collaboration with obstetric teams will be required for management of critically ill pregnant patients. Neonatal ICUs may need to work with adult critical care teams to gain access to additional neonatalcapable mechanical ventilators and monitoring equipment for their patients, or may face requests to share their ventilators to support an adult critical care surge.

For these special groups of potentially critically ill patients, the critical care team and hospital at large should take account of space, equipment, supplies, and staff to help manage surges for those groups. In the absence of expertise to manage these patient populations, hospitals should consider planning to leverage telemedicine technology ${ }^{15-17}$ to gain assistance from clinical experts at a remote site (which may be different than their usual partners who may be also affected by the disaster and unable to assist).

\section{Laboratory and Diagnostic Imaging Services}

From an all-hazards perspective, a disaster can change the need for laboratory and diagnostic imaging support because of the increased demand for tests and the need for rapid, point-of-care results to minimize delay in clinical decision making and triage decisions during mass casualty events. From a laboratory perspective, disaster planning should incorporate strategies for triaging of laboratory study requests to maximize time-sensitive results impacting on critical clinical decision making. Use of existing or stockpiled portable point-of-care laboratory equipment that can be operated by frontline clinical staff can be considered to reduce burden on the laboratory team. Bedside clinical monitoring may be used as a laboratory test mitigation strategy in some cases, such as the use of pulse oximetry and quantitative capnography for ventilated patients instead of arterial blood gas testing, or advanced pulse oximeters that can measure carbon monoxide levels as a screening strategy in mass casualty carbon monoxide exposure. ${ }^{18}$ Certain high-priority threats identified by the ICU-specific HVA may warrant specific discussion with laboratory services to ensure availability of necessary hazard-specific testing if possible. Blood bank services in particular will need to coordinate with critical care and other hospital services to prepare for mass casualty events placing excessive demands for blood products, including a strategy to triage blood product requests in extreme cases. 
During a disaster, demand for diagnostic imaging studies may outstrip capacity of available equipment and technologists, and availability of radiologists to interpret the studies. Use of portable radiographic equipment with an integrated monitor to allow immediate review of images by frontline clinicians may reduce delay in detection of critical clinically important findings. Planning for enhanced availability of point-of-care ultrasound can be helpful as a substitute for other diagnostic imaging modalities, or to help triage cases when resources are limited, such as prioritizing computed tomography scan requests for possible abdominal injuries or ruling out of a pneumothorax and avoiding need for portable radiographic equipment. ${ }^{19}$ Other newer point-of-care technology may help identify patients at higher risk for neurosurgical intervention and again help prioritize patients for access to limited diagnostic resources. ${ }^{20}$

\section{Facilities and Information Technology}

An essential element of critical care disaster planning assumes the high likelihood of having to manage critically ill patients outside of the usual ICU space. Ensuring that appropriate physical plant and space is available, along with information technology support, will reduce some challenges with regard to working in non-ICU space. Understanding of space capabilities, with the input of facilities engineers, can help with the appropriate planning choices for ICU surge space within the hospital and help avoid unpleasant surprises, such as lack of emergency backup power outlets, sufficient medical gas supply, or other limitations. A particular concern is the availability of negative-pressure airborne isolation rooms in the event of a serious airborne-spread biohazard disaster. Most hospitals have limited airborne isolation capacity during usual operations. During hospital surge experiences during the worldwide 2012 to 2013 Severe Acute Respiratory Syndrome (SARS) outbreak, some facilities were able to modify airflow and erect barriers to create large negative-pressure isolation wards, including ICUs. ${ }^{21}$ Planning for various scenarios identified in the ICU-specific HVA should identify potential physical facility gaps and prompt mitigation strategies.

Intensive care units are technology-dependent areas of care that rely on sophisticated information technology services for networking of patient care monitors and equipment, electronic drug dispensing modules, and computer access to support ICU-specific electronic medical records. In disaster situations, initial receipt of patients in the ED will often shift to a paper-based triage and registration strategy. Planning for the transition from the initial crisis phase of a disaster with mass casualties to integration of patients within the electronic medical record will help ensure timely and accurate access and creation of health provider notes, laboratory results, and diagnostic imaging reports. Information technology services should also plan for additional need of mobile computers and sufficient wireless network access to manage critically ill patients outside of the usual ICU space. The potential need for use of telemedicine services to support management of special populations of patients, as mentioned above, should prompt planning and testing of telemedicine capacity including equipment and network bandwidth in advance to prevent service gaps during a disaster.

\section{Security}

Hospitals typically spend considerable effort and resources on controlling external access to the facility during disaster events to ensure patient and staff safety, deter premature entry of persons requiring decontamination, maintain control of limited resources and supplies, and prevent unauthorized members of the media or other members of the public from compromising patient and family privacy. ${ }^{22}$ In the event of strict hospital visitor restrictions, attempts to circumvent security controls can be expected. Specific consideration of the security needs of the critical care areas 
(traditional and makeshift) is occasionally overlooked. Intense emotional reactions of family and friends of critically ill patients can occur and be compounded in a stressful disaster situation. In the event of implementation of triage activities and a shift from usual standards of care, decisions to withdraw life support from those patients not benefiting from scarce resources can be met with violent objection. Physical measures to limit access to the critical care areas may need enhancement, and there may also be a need for greater visible presence of security staff as a deterrent to unacceptable treatment of hospital staff. Liaison with security staff should be included as part of the critical care disaster planning process to avoid gaps in security capability.

\section{Administration and Finance}

Disaster preparedness requires an investment of resources in terms of staff time to commit to planning, equipment, and supplies earmarked for disaster stockpiling, and development of relationships and agreements with external entities. For preparedness to be effective, hospital administration must appreciate the need for planning and endorse recommendations. Although the finance elements within a hospital are usually prepared to capture costs incurred while a disaster is in progress to facilitate reimbursement, advance efforts to secure funding support for disaster preparedness through government and other agency grants can mitigate opposition to diversion of funds away from frontline clinical activities. Increasingly, hospitals are appointing a lead for disaster preparedness who can act as a liaison between clinicians and administration. Given the high costs that can be associated with provision of critical care, particularly in surge situations, clear articulation of the needs for critical care disaster planning may enable the necessary allocation of resources to ensure the planning vision is realized.

\section{HOW CAN WE TEACH, TEST, AND TWEAK THE CRITICAL CARE DISASTER PLAN?}

Certainly, lessons can be learned after each disaster event that can lead to identification of problems or gaps in a critical care disaster plan. Fortunately, those disaster events are uncommon, but, unfortunately, we cannot rely only on actual disaster events to test plans and maintain disaster competency among hospital staff. Frequent disaster exercises can help educate staff on how to function during an actual event, and provide feedback to disaster planners allowing plan improvement before a disaster. Disaster exercises may vary in scale and fidelity (Fig. 1). The scale of a disaster exercise may be limited to a single critical care unit, involve multiple hospital services, or be expanded to a regional, state, or even national scale. The fidelity of a disaster exercise may be tabletop-based, using patient cards and virtual clinical spaces; may take into account current actual clinical volumes and bed availability; or may use hundreds of actors playing the role of patients, combined with highfidelity patient simulators, scattered throughout actual areas of the hospital for an in-situ exercise. ${ }^{23}$ Exercises of greater fidelity and greater scale consume more resources to conduct, and may be more likely to interfere with routine hospital operations. However, the greater the fidelity and the greater the scale, the more likely it will be to identify opportunities for improvement in disaster planning. Thus, a balance of these factors must take into account local resources, support for disaster preparedness by hospital leadership, and mandatory activities required for hospital accreditation or government funding.

Beyond generic disaster exercise activities, certain aspects of disaster planning specific to critical care should be specifically addressed in exercise design. Critical care leaders and staff should understand the Hospital Incident Command System (HICS) ${ }^{24}$ 


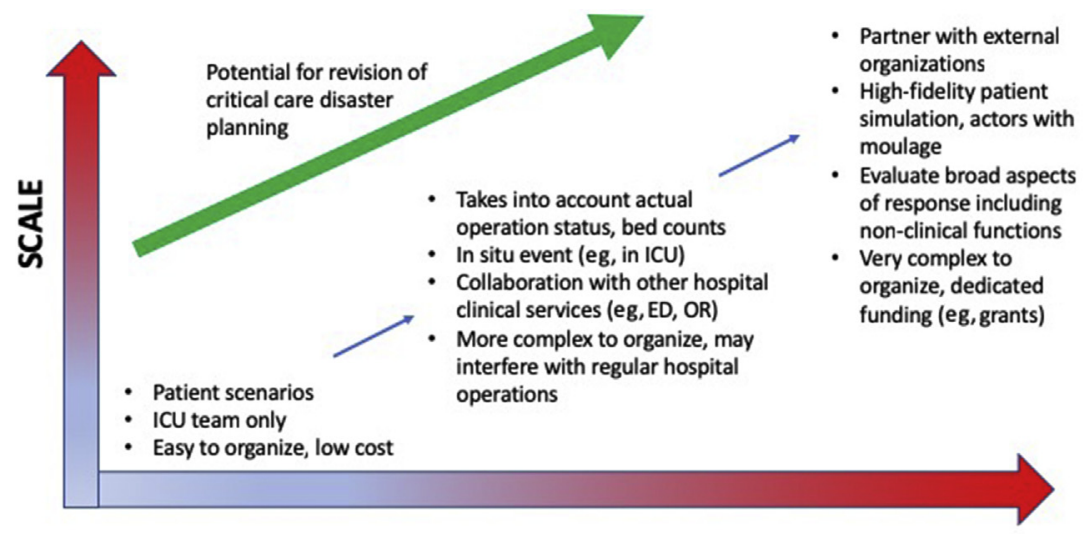

FIDELITY

Seminar/workshops

Tabletop exercises

Drill Functional exercise

Full scale exercise

Fig. 1. Design of critical care disaster exercises taking into account scale and fidelity of planned events.

as organized in their hospital, and know how they interface with the HICS. Critical care would normally fit within the Operations branch, under control of the Operations Chief. In some cases, leadership roles within the HICS may be filled by critical care leaders given their broad clinical understanding of the hospital as a whole; however, their responsibilities would be guided by the HICS role rather than keeping a narrow focus on critical care. Depending on the nature of the disaster event, critical care leaders and clinicians may be asked to assist the HICS leadership team as subject matter experts, or participate in task forces or strike groups designed to handle specific problems. Certain principles of the HICS can be useful in disaster planning on a smaller scale specific to critical care. The concept of span of control, having everyone report to only 1 person, and each person only having 5 to 7 people reporting to them, may be helpful in organizing clinical teams including non-ICU staff supervised by ICU clinicians. Also, the concept of job action sheets that provide guidance for key actions given a particular role can be helpful in reminding staff of key tasks during a stressful disaster event, and can be a valuable teaching tool during an exercise.

Hospital exercises often emphasize infrequent but important tasks, such as decontamination of patients before entry to hospital, which are important but potentially less relevant to critical care staff. Patients should never enter a critical care area without decontamination if required. For biological infectious events, there may be no ability to perform the equivalent of decontamination, because the patients remain infectious and put staff and other patients at risk. Exercise and evaluation of advanced infection control strategies (such as conversion to negative-pressure clinical areas, use of infection control coaches), or advanced personal protective equipment (such as powered air-purifying respirator use, safe donning and doffing of equipment) may be of special significance for critical care team preparedness. Exercises should also encourage familiarity with stockpile equipment, such as monitoring equipment or unfamiliar ventilators, so that there is some retention of competency in the event of the need to use such equipment in a disaster event. Just-in-time education strategies to augment clinical care for special populations (eg, pediatrics) or hazard-specific care (eg, radiation sickness) can be practiced and evaluated for future revision.

Much of the learning from a disaster exercise takes place during the debriefing phases after the event. A "hotwash" debriefing immediately after the event can 
capture important lessons; however, another opportunity to capture additional lessons after some time to reflect can also provide further guidance on disaster plan revisions. Preparing an after-action report after simulated and real disasters can ensure that lessons learned are captured; however, development of a list of actions including accountabilities and timelines, with a process for follow-up to ensure completion, should reduce the rediscovery of the same recommendations at the next real or simulated disaster.

\section{SUMMARY}

The preparedness phase of disaster management can make or break the response to an actual disaster. Teams should aim for an optimal balance between flexible all-hazards preparedness and hazard-specific preparedness guided by the hazardvulnerability assessment. One of the best strategies for ensuring ongoing support for disaster preparedness activities is to identify potential flaws in the current disaster plan through frequent disaster exercises. Despite the temptation to divert resources to routine clinical budget demands, an upfront investment in preparedness will hopefully lead to a more efficient disaster response and more rapid recovery to normal operations should a disaster occur.

\section{REFERENCES}

1. Kollek D, Jarvis C. Disaster preparedness: are we ready yet? Hospital News 2019. Available at: https://hospitalnews.com/33869-2/. Accessed June 16, 2019.

2. Gregory AP. Reassessing the effectiveness of all-hazards planning in emergency management. Inquiries Journal 2015. Available at: http://www. inquiriesjournal.com/ articles/1050/reassessing-the-effectiveness-of-all-hazards-planning-in-emergencymanagement. Accessed June 16, 2019.

3. Hazards vulnerability analysis. Emergency preparedness: California Hospital Association. Available at: https://www.calhospitalprepare.org/hazard-vulnerabilityanalysis. Accessed June 16, 2019.

4. Shirley PJ, Mandersloot G. Clinical review: the role of the intensive care physician in mass casualty incidents: planning, organisation, and leadership. Crit Care 2008;12(3):214.

5. Loke AY, Fung OW. Nurses' competencies in disaster nursing: implications for curriculum development and public health. Int J Environ Res Public Health 2014;11(3):3289-303.

6. American Association of Nurse Anesthetists. Guidelines regarding the role of the certified registered nurse anesthetist in mass casualty incident preparedness and response. 2014. Available at: https://www.aana.com/docs/default-source/ practice-aana-com-web-documents-(all)/guidelines-regarding-the-role-of-the-crnain-mass-casualty-incident-preparedness-and-response.pdf?sfvrsn=870049b1_4. Accessed June 16, 2019.

7. Laberge ML. Creating a disaster plan for RT departments. Can J Respir Ther 2017;53(2):42-3.

8. Bell C, Daniel S. Pharmacy Leader's role in hospital emergency preparedness planning. Hosp Pharm 2014;49(4):398-404.

9. Biddison LD, Berkowitz KA, Courtney B, et al. Ethical considerations: care of the critically ill and injured during pandemics and disasters: CHEST consensus statement. Chest 2014;146(4 Suppl):e145S-55S. 
10. Maunder RG, Lancee WJ, Mae R, et al. Computer-assisted resilience training to prepare healthcare workers for pandemic influenza: a randomized trial of the optimal dose of training. BMC Health Serv Res 2010;10:72.

11. Aiello A, Khayeri MY, Raja S, et al. Resilience training for hospital workers in anticipation of an influenza pandemic. J Contin Educ Health Prof 2011;31(1):15-20.

12. American Society of Anesthesiologists Committee on Trauma and Emergency Preparedness. Emergency preparedness: manual for anesthesia department organization and management. Available at: https://www.asahq.org/ /media/sites/ asahq/files/public/resources/asa\%20committees/madom\%20emergency\%20 preparedness\%20chapter-final.pdf. Accessed June 16, 2019.

13. Western New York Pediatric Surge Work Group. WNY hospital pediatric disaster preparedness presentation 2014-15. Available at: https://www.urmc.rochester. edu/MediaLibraries/URMCMedia/flrtc/documents/WNY-Pediatric-WG-PlanningSteps-for-Hospitals-2014-15_2.ppt. Accessed June 16, 2019.

14. New York City Pediatric Disaster Coalition and New York City Department of Health and Mental Hygiene. Recommendations for increasing NYC pediatric critical care surge capacity (Draft). 2009. Available at: https://www.urmc.rochester. edu/MediaLibraries/URMCMedia/fIrtc/documents/hepp-pedsconfO2-rec-for-incrpicu-surge.pdf. Accessed June 16, 2019.

15. Harvey JB, Yeager BE, Cramer C, et al. The impact of telemedicine on pediatric critical care triage. Pediatr Crit Care Med 2017;18(11):e555-60.

16. Ellenby MS, Marcin JP. The role of telemedicine in pediatric critical care. Crit Care Clin 2015;31(2):275-90.

17. Sauers-Ford HS, Marcin JP, Underwood MA, et al. The use of telemedicine to address disparities in access to specialist care for neonates. Telemed J E Health 2018. https://doi.org/10.1089/tmj.2018.0095.

18. Sebbane M, Claret PG, Mercier G, et al. Emergency department management of suspected carbon monoxide poisoning: role of pulse CO-oximetry. Respir Care 2013;58(10):1614-20.

19. Alrajhi K, Woo MY, Vaillancourt C. Test characteristics of ultrasonography for the detection of pneumothorax: a systematic review and meta-analysis. Chest 2012; 141(3):703-8.

20. Leon-Carrion J, Dominguez-Roldan JM, Leon-Dominguez U, et al. The Infrascanner, a handheld device for screening in situ for the presence of brain haematomas. Brain Inj 2010;24(10):1193-201.

21. Loutfy MR, Wallington $T$, Rutledge $T$, et al. Hospital preparedness and SARS. Emerg Infect Dis 2004;10(5):771-6.

22. Sarr E, McGlen K. Lessons healthcare security professionals learned from Hurricane Harvey. Security Management. Alexandria (VA): ASIS International; 2019. Available at: https://sm.asisonline.org/Pages/Lessons-Healthcare-SecurityProfessionals-Learned-from-Hurricane-Harvey.aspx. Accessed June 16, 2019.

23. World Health Organization. Hospital and health facility emergency exercises: guidance materials. 2010. Available at: http://www.wpro.who.int/publications/ docs/HospitalandHealthFacilityEmergencyExercisesforWeb. pdf. Accessed June 16, 2019.

24. Emergency Medical Services Authority California. Hospital incident command system guidebook. 5th edition 2014. Available at: https://emsa.ca.gov/wp-content/ uploads/sites/71/2017/09/HICS_Guidebook_2014_11.pdf. Accessed June 16, 2019. 